\title{
Currency Paper from Waste Textile Lint Fibers: Nanofibrillated Cellulose and Combined System of Starch-nanocellulose and Polyacrylamide-nanocellulose Substituting for Long-fiber Chemical Pulp
}

\author{
Jafar Ebrahimpour Kasmani *
}

Nanofibrillated cellulose (NFC) and a combined systems of NFC with cationic starch or cationic polyacrylamide were used in place of long-fiber chemical pulp in manufacturing currency paper from waste lint fibers from the textile industry. Handmade papers $(60 \mathrm{~g})$ were produced from each treatment, and the physical, mechanical, and optical characteristics of papers were compared. The results showed that increasing amounts of NFC by itself increased tensile strength, resistance to bursting, tearing, porosity, and opacity, and decreased the resistance to folding and brightness. Increasing NFC in combination with cationic starch reduced the need for chemical pulp, while improving porosity, opacity, and brightness and increased tensile strength, bursting strength, resistance to tearing, and folding in comparison to the use of long-fiber pulp. Increasing NFC in combination with cationic polyacrylamide, compared to long-fiber chemical pulp, increased opacity, tensile strength, and resistance to bursting and decreased the porosity, resistance to tearing, folding, and brightness. Field emission-scanning electron microscopy results showed that an enhanced percentage of NFC reduced porosity so that addition of $5 \%$ cellulosic nanofiber made the paper surface smoother and pores were relatively filled.

Keywords: Cellulosic nanofibers; Long-fiber chemical pulp; Waste lint fiber; Currency paper; Chemical; Physical and optical characteristics

Contact information: Department of Wood and Paper Science Engineering, Savadkooh Branch, Islamic Azad University, Savadkooh, Iran; *Corresponding author: Jafar_kasmani@yahoo.com

\section{INTRODUCTION}

Regarding the application of nanotechnology in different industrial areas, using nanoparticles in the papermaking industry has gained special interest, and its innovation and application have been gradually developed. Recently, utilizing lignocellulosic nanofibers has drawn attention as a novel additive for improving paper strength properties (Rodriguez 2005; Asadpour et al. 2015; Moradian et al. 2015). Recent studies have highlighted the role of nanofibrillated cellulose (NFC) in improvement of paper strength properties (Hassan et al. 2011; González et al. 2012; Hii et al. 2012; Hadilam et al. 2013). It has been found that the addition of NFC can reduce porosity and increase internal bonding and resistance against air passage (Hii et al. 2012; Charani et al. 2013; Sehaqui et al. 2013). Studies have indicated that using NFC can increase tensile strength and bonding between fibers, but sometimes it can reduce tearing strength of paper and slow the drainage of water during the paper forming process (Hadilam et al. 2013). In most of the studies on the application of NFC in papermaking, a cationic polymer was used as a retention aid 
(Charani et al. 2013; Petroudy et al. 2014; Rice et al. 2018). Nevertheless, generally, adding cationic polymer prior to nanoparticles with negative charge can have a more positive effect on mechanical resistance characteristics of the resulting paper, such as the addition of nanolignocellulosic material to paper pulp suspension (Elyasi et al. 2016). Nonetheless, if cationic polymer is added after nanoparticles with negative charge, a more positive effect in durability of anionic nanoparticles and reduction of drainage level can be expected due to curdling action (Hamzeh and Rostampur-Hafthkani 2008). It follows that, by suitable adjustments, researchers can expect to achieve more appropriate mechanical properties in paper by maximum durability of NFC in the paper structure.

The overall price of the targeted product can be reduced significantly if researchers gain proper results in combination with waste lint fibers with treated chemical pulps via dry additives such as starch and cationic polyacrylamide. The inter-fiber bonds will be increased by using the dry-strength additives (Hamzeh and Rostampur-Hafthkani 2008). In addition, dry-strength additives can reduce basic weight through enhancement of strength properties; therefore, the paper machine speed may be increased (Hubbe 2005). Commonly used dry-strength additives can be described as water-soluble polymers that are able to form hydrogen bonds. Starch and its derivatives are among common dry additives that are used in the papermaking industry. Starch with various mechanisms increases dry properties of paper sheets (Hamzeh and Rostampur-Hafthkani 2008). Addition of NFC in combination with cationic polyacrylamide has been found to improve the drainage process and increase the durability of papers (Tajik et al. 2016).

The manufacturing of currency paper is more complicated than that of printing and writing paper because the product must meet various criterion standards, which are different from other grades of printing and writing papers (Fathi and Kasmani 2019). In a spinning factory, after opening the bales of cotton, the fibers are split and the grains are separated. This action is named combing. Cotton with long-fibers has mostly been used for producing high quality yarn. Therefore, the cotton material has been passed through a needle hook to separate the short and rough fibers. This action is called combing the cotton fiber. To clean the cotton fiber, winding and accelerator devices are used to separate impurities via centrifugal force. In the combing stage of long cotton fiber, there is a plate under the hooks that has determined diameter meshes, and short fibers (the waste lint) pass from it and collect under the combing plate (Fathi and Kasmani 2019). These fibers are not suitable for the textile industry because of their short length and roughness. Therefore, in comparison with long-fibers, they have lower economic value. Due to the properties of the waste lint fibers (in terms of length and diameter), they have been used in the pulp and paper industry as a primary raw material, especially for manufacturing durable papers, such as currency paper (Hubbe 2020). Using waste lint fibers reduces the destructive effects of over-harvesting wood from the forest, and they have also drawn the attention of producers of special papers regarding their intrinsic strength and purity. However, the needed strength characteristics cannot be achieved in the production of currency paper merely by using waste lint fibers. To compensate for the reduction of strength properties, long-fiber chemical pulp typically needs to be used in addition to the cotton fiber. However, chemical fibers not only produce problems for companies economically, but also sometimes, their preparation is not easy. The present study considered separate and combined additives of NFC along with optional starch and cationic polyacrylamide treatment of NFC to be used in place of long-fiber chemical pulp. The aim of this study was to determine the optimum level of addition of NFC along with starch and cationic polyacrylamide to waste lint paper pulp for feasibility of its substitution for long-fiber chemical pulp at a laboratory scale. 


\section{EXPERIMENTAL}

\section{Materials}

Pulp

In this study, refined paper pulp of waste lint and long-fiber chemical pulp were transferred from a durable paper manufacturer (Ehpak Ind. Co., Sari, Iran) to laboratory (Karaj, Iran). The resulting pulps were dewatered to a concentration of 10 to $15 \%$ and then placed in a plastic bag and kept in a refrigerator until use.

\section{Cellulosic nanofibers}

Nanofibrillated cellulose (NFC) was prepared by Nano Novin Polymer Co. (Gorgan, Iran). The NFC was produced using bleached chemical-mechanical paper pulp from Mazandaran Wood and Paper Co. (Sari, Iran). The average diameter of the nanomaterials was less than $50 \mathrm{~nm}$.

\section{Polyacrylamide}

Polyacrylamide was prepared according to the method of Charani et al. (2013). First, $0.01 \mathrm{~g}$ of polyacrylamide with a molecular weight of $359,000 \mathrm{~g} / \mathrm{mol}$ was poured into a 100-mL flask. Then, $1.5 \mathrm{~mL}$ ethanol was added to it. After $2 \mathrm{~min}, 50 \mathrm{~mL}$ of distilled water was added to the flask and it was hand shaken for $2 \mathrm{~min}$. The contents of the flask were magnetically stirred for $3 \mathrm{~h}$. The flask containing the polymer was kept in a refrigerator for $24 \mathrm{~h}$. Then, at the time of use, the contents of the flask reached to the volume of $100 \mathrm{~mL}$ by addition of distilled water, and all the materials were stirred for $10 \mathrm{~min}$. The resulting polymer solution, having a concentration of $0.01 \%$, was used for increasing the durability of cellulosic nanofiber in the paper pulp suspension. Polyacrylamide was added at three levels of $0.05,0.1$, and $0.15 \%$ on the basis of dry weight of pulp from $1 \%$ polyacrylamide solution.

\section{Cationic starch}

Potato base cationic starch was prepared by Lyckeby Amylex Co. from Horažd'ovice, Czechia. The $\mathrm{pH}$ of cationic starch was about 6, replacement degree of this starch was $0.035 \mathrm{~g} / \mathrm{mol}$, its protein level was $1.5 \%$, protein level was $25 \%$, and ash was $1 \%$. To produce the starch solution, $0.5 \mathrm{~g}$ of it was measured, and it was added to sufficient distilled water to reached $100 \mathrm{~mL}$ volume. The round-bottomed flask content was stirred on a heater for $20 \mathrm{~min}$. This solution was used at three levels of $0.5,1$, and $1.5 \%$ in suspension of refined pulp based on dry weight of pulp with a mixing time of $15 \mathrm{~min}$. The cationic starch properties are presented in Table 1.

Table 1. Cationic Starch Properties

\begin{tabular}{|c|c|}
\hline Properties & Value \\
\hline Moisture & $14 \%$ \\
\hline Gelation Temperature & $70{ }^{\circ} \mathrm{C}$ \\
\hline Cooking Temperature & $90{ }^{\circ} \mathrm{C}$ \\
\hline $\mathrm{pH}$ & 6 \\
\hline Viscosity & $75.7 \mathrm{cp}$ \\
\hline Degree of substitution (DS) & 0.035 \\
\hline
\end{tabular}




\section{Methods}

Preparation of handsheets

After the preparation of chemical paper pulp and cotton pulp, for the addition of cellulosic nanofiber, polyacrylamide, and starch, the 13 separated treatments were considered as listed in Table 2.

According to Table 2, $60 \mathrm{~g} \cdot \mathrm{m}^{-2}$ handsheets were made based on the standard regulations according to TAPPI T205 sp-02 (2002) and by the means of handsheet forming equipment. Ten samples of sheets were made for each treatment.

Table 2. Combination of Treatments and Consumption Levels of Cellulosic Nanofibers, Cationic Starch, and Polyacrylamide

\begin{tabular}{|c|c|c|c|c|c|c|}
\hline $\begin{array}{c}\text { Treatment } \\
\text { Number }\end{array}$ & $\begin{array}{c}\text { Treatment } \\
\text { Code }\end{array}$ & $\begin{array}{c}\text { Waste } \\
\text { lint }\end{array}$ & $\begin{array}{c}\text { Long- } \\
\text { fiber } \\
\text { Chemical } \\
\text { Pulp }\end{array}$ & $\begin{array}{c}\text { Cellulosic } \\
\text { Nanofiber }\end{array}$ & $\begin{array}{c}\text { Cationic } \\
\text { Starch }\end{array}$ & Polyacrylamide \\
\hline 1 & OLP & 100 & 0 & 0 & 0 & 0 \\
\hline 2 & $10 \mathrm{LP}$ & 90 & 10 & 0 & 0 & 0 \\
\hline 3 & $20 \mathrm{LP}$ & 80 & 20 & 0 & 0 & 0 \\
\hline 4 & $30 \mathrm{LP}$ & 70 & 30 & 0 & 0 & 0 \\
\hline 5 & $5 \mathrm{NC}$ & 95 & 0 & 5 & 0 & 0 \\
\hline 6 & $5 \mathrm{NC}+1 \mathrm{CS}$ & 94 & 0 & 5 & 1 & 0 \\
\hline 7 & $5 \mathrm{NC}+$ & 94.9 & 0 & 5 & 0.1 & 0 \\
\hline 8 & $0.1 \mathrm{PAM}$ & & & 0 & 0.5 & 0 \\
\hline 9 & $0.5 \mathrm{CS}$ & 99.5 & 0 & 0 & 1 & 0 \\
\hline 10 & $1 \mathrm{CS}$ & 99 & 0 & 0 & 1.5 & 0 \\
\hline 11 & $1.5 \mathrm{CS}$ & 98.5 & 0 & 0 & 0 & 0.05 \\
\hline 12 & $0.05 \mathrm{PAM}$ & 99.95 & 0 & 0 & 0 & 0.1 \\
\hline 13 & $0.1 \mathrm{PAM}$ & 99.9 & 0 & 0 & 0 & 0.15 \\
\hline
\end{tabular}

Measurement of the paper properties

A summary of the physical, mechanical, and optical characteristics of sheets tested is provided in Table 3, along with the national and international standards.

Table 3. Tested Physical and Mechanical Characteristics

\begin{tabular}{|c|c|c|}
\hline No. & Properties Tested & Standard Number \\
\hline 1 & Porosity & TAPPI T460 om-02 (2002) \\
\hline 2 & Surface smoothness & TAPPI T555 om-04 (2004) \\
\hline 3 & Tensile strength index & TAPPI T494 om-01 (2001) \\
\hline 4 & Folding strength & TAPPI T423 cm-98 (1998) \\
\hline 5 & Burst resistance index & TAPPI T403 om-02 (2002) \\
\hline 6 & Tear resistance index & TAPPI T414 om-04 (2004) \\
\hline 7 & Brightness, and opacity & TAPPI T452 om-98 (1998) \\
\hline
\end{tabular}

Field emission scanning electron microscopy (FE-SEM)

In this study a MIRA3 TESCAN electron microscope, manufactured by TESCAN, Libušina, Czech Republic, set at a $0.5 \mathrm{kV}$ to $30 \mathrm{kV}$ accelerating voltage, was used. 


\section{Statistical analysis}

The statistical plot of the present study was completely random. To perform data analysis, a one way variance analysis was conducted and mean grouping was completed using the Duncan test at $95 \%$ assurance level via SPSS software (IBM Software, v.23, Armonk, NY, USA).

\section{RESULTS AND DISCUSSION}

The F-value amount and significant levels are shown in Table 4.

Table 4. Variance Analysis (F-value and Significance Level)

\begin{tabular}{|c|c|c|c|c|c|c|c|c|}
\hline 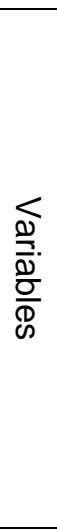 & 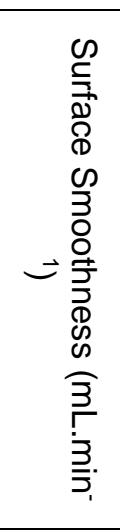 & 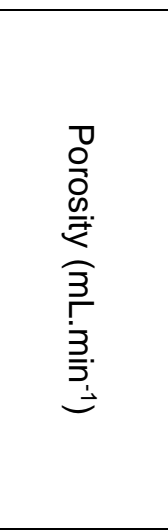 & 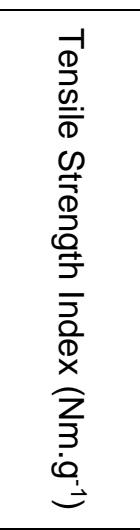 & 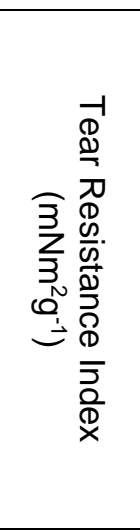 & 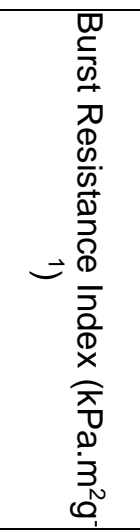 & 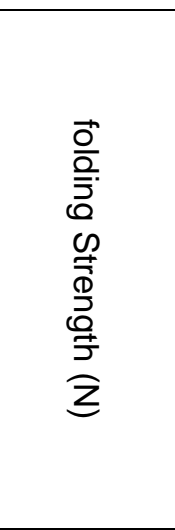 & 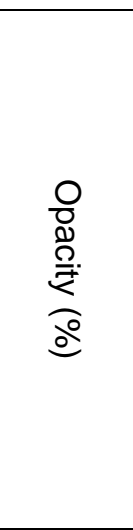 & 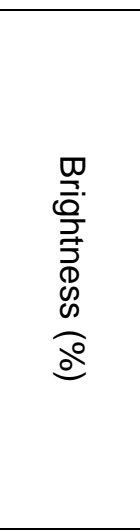 \\
\hline & $5.925^{*}$ & $125.053^{*}$ & $17.494^{*}$ & $19.273^{*}$ & $17.833^{*}$ & $2896.657^{*}$ & $14.619^{*}$ & $14.300 *$ \\
\hline
\end{tabular}

Significance level: $95 \%$, ns: no significance

\section{Surface smoothness}

Surface smoothness is one of the most crucial structural characteristics. Smoothness has gained importance in specific functions, especially for better printability and print quality (Elyasi et al. 2016). This characteristic is mainly affected by the average of fibers' length and presence of voids and their stability in the paper network and their formation quality. For example, the curdling of microparticles can improve paper smoothness (Hamzeh and Rostampur-Hafthkani 2008). As shown in Fig. 1, the lowest surface smoothness level was due to the application of $5 \%$ nanocellulose and $1 \%$ cationic starch, which was equal to $1067 \mathrm{~mL} / \mathrm{min}$, and the highest level was related to the emergence of $0 \%$ imported chemical fibers, which was equal to $2667 \mathrm{~mL} / \mathrm{min}$.

\section{Porosity}

Porosity indirectly indicates the inner structure of paper that is affected by the uniformity of paper formation and the manner of fibers, voids, and fillers' distribution, and somehow shows the function of retention aid material in creation of flocs and the manner of their dispersion. Usually, the level of paper porosity is reduced by improvement of paper's uniformity of formation (Akbarpour and Resalati 2011). Duncan's test categorized various means of porosity into 5 different classes. Figure 2 shows that the highest level of porosity was due to the utilization of $1.5 \%$ cationic starch, which corresponded to 2100.0 $\mathrm{mL} / \mathrm{min}$, and the lowest level was related to the application of $0.15 \%$ polyacrylamide, which corresponded to $1700.0 \mathrm{~mL} / \mathrm{min}$. 


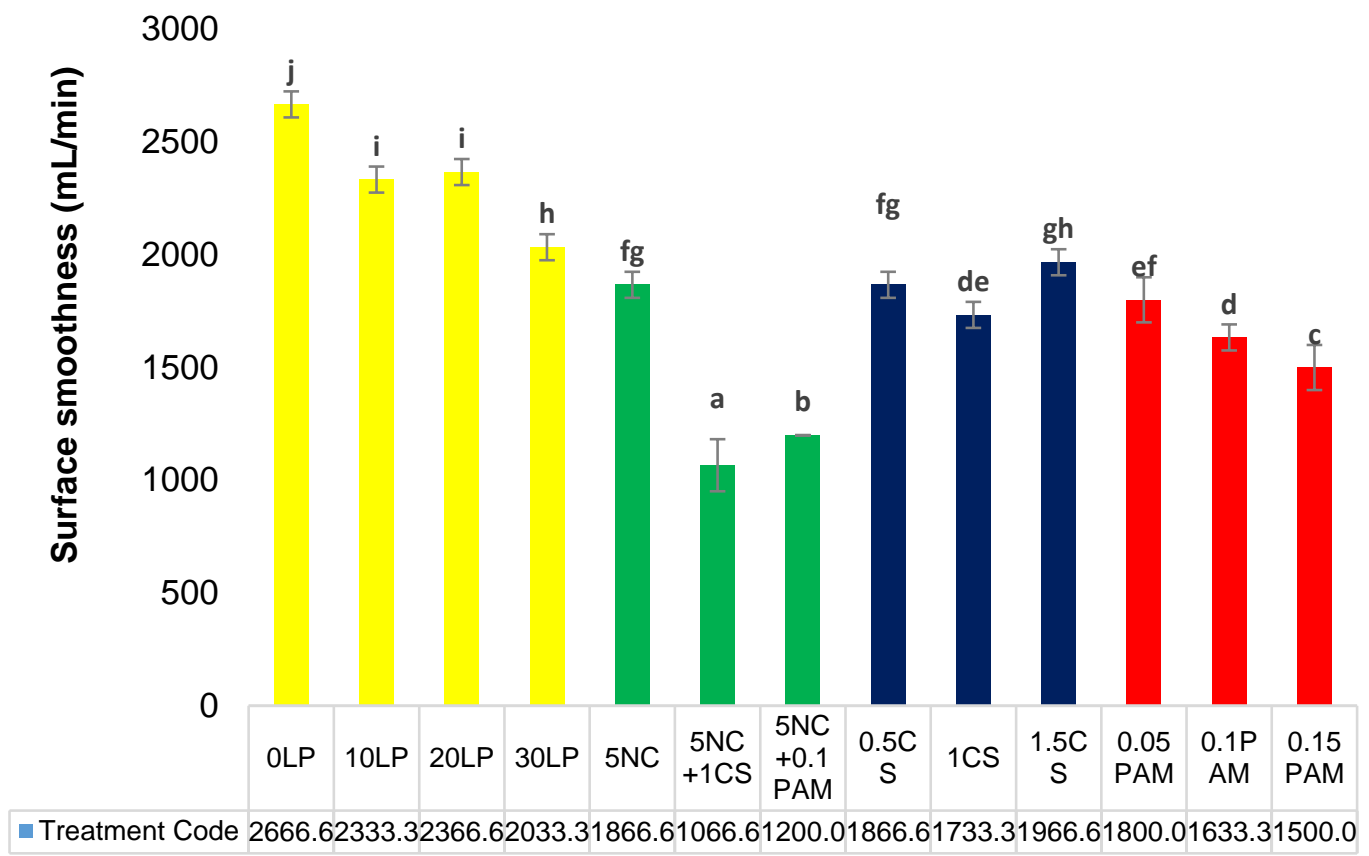

Fig. 1. Mean comparisons of paper surface smoothness and grouping the means

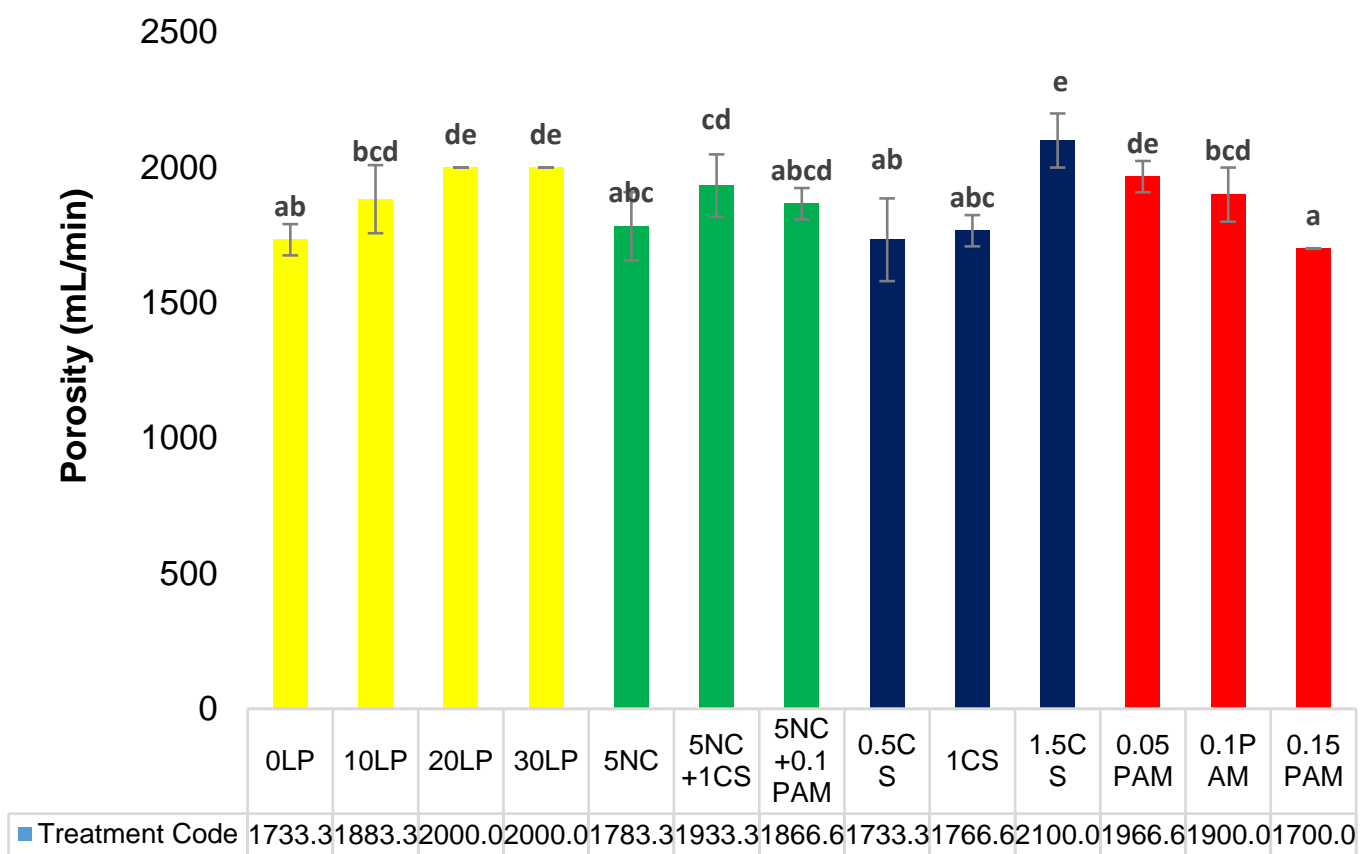

Fig. 2. Mean comparisons of paper porosity and grouping the means

As the size of cellulosic nanofibers became smaller, their specific surface increased. This means that there were more available hydroxyl groups at the surface of nanofibers that are able to create hydrogen bonds with their adjacent nanofibers, and eventually they create a network of nanofibers (Yousefi et al. 2011). All the aforementioned procedures tend to reduce the porosity. The positive charge of cationic starch and its strong tendency toward adsorbing on the negatively charged fibers causes an improvement of bonding 
between fibers and reduction of porosity. Hii et al. (2012) showed via SEM images that cellulosic nanofibers help to join the fillers with micro fiber particles and reduce paper porosity; in addition, it enhances the resistance of paper against air flow passage and better interbonding in the paper sheets (Nazeri 2007). Better dispersion of cellulosic nanofibers reduces porosity (Hubbe and Gill 2004).

\section{Tensile strength index of handsheets}

Figure 3 compares the mean of tensile strength index for 13 types of paper pulp. Duncan's grouping organized the mean of tensile strength index into 6 different classes. The highest tensile strength was obtained by applying $1.5 \%$ cationic starch and a treatment combination of $5 \%$ NFC with $1 \%$ starch. Tensile strength is regarded as a preferred index for all the interfiber bonding that is due to a combination of other strengths (Kasmani et al. 2013). Tensile strength is affected by the intrinsic strength of fibers and strength of interfiber bonding. Because the addition of nanocellulose and starch cannot change the inherent strength of fibers, in fact, more absorbance of the polymer on NFC, especially cationic starch, increased the connectivity between fibers and then tensile strength of papers. Moreover, as the size of particles became smaller, the specific surface of cellulosic fibers increased. This means that more hydroxyl groups are available to form hydrogen bonds with adjacent nanofibers and eventually they form a network of nanofibers and increase this strength (Yousefi et al. 2011).

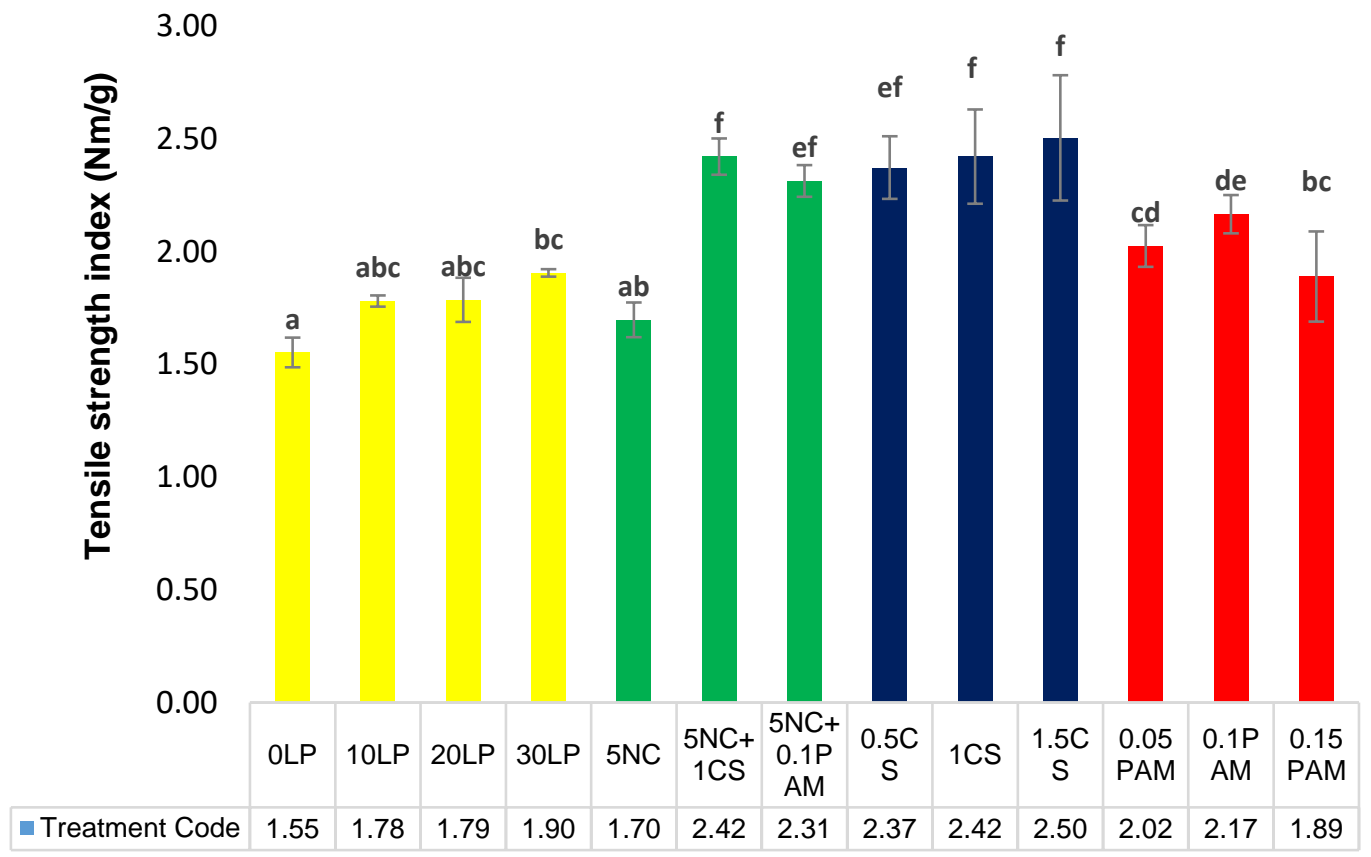

Fig. 3. Mean comparisons of paper tensile strength and grouping the means

Because cellulosic nanofibers have high specific surface and cause physical involvement with the fibers of paper pulp, hydrogen bonds, and interfiber joints are enhanced and as a result more strength is obtained between the fibers. This means that more hydroxyl groups are available. They are able to form hydrogen bonds with adjacent nanofibers, and eventually they cause to form a network of nanofibers and increase this strength (Yousefi et al. 2011). 
Rezayati et al. (2013) used cellulosic nanofibers in papermaking and reported that using $6 \%$ cellulosic nanofiber improves tensile strength and this amount is equal to using $20 \%$ long-fiber paper pulp in papermaking from kraft pulp (Charani et al. 2013).

Addition of polyacrylamide individually and starch individually and in the combination of nano cellulose has led to maximum level of tensile strength. In fact, polyacrylamide and starch as long chain polymer with cationic charge density can cause proper formation and durable papers by joining to fiber surface and making bridges between components of paper dough slurry. The overall result of the additives is to increase paper's density and improve bonding quality, and eventually result in the highest tensile strength. In addition, NFC can increase the extent of hydrogen bonding and bonding surface between fibers because of high specific level and making physical engagement among fibers; greater strength of fiber network is the result of such actions. Non-significant amounts in these four treatments and resistance fluctuations resulted from differences in charge balance of suspension at various levels of using NFC, starch, and polyacrylamide; this is understandable according to durability of mostly non-fibrous components and considering the nature of fibers suspensions.

\section{Bursting strength index of handsheets}

Figure 4 shows the mean of the bursting strength index for 13 types of paper pulp. Duncan's grouping put the mean of bursting strength index into 7 different classes.

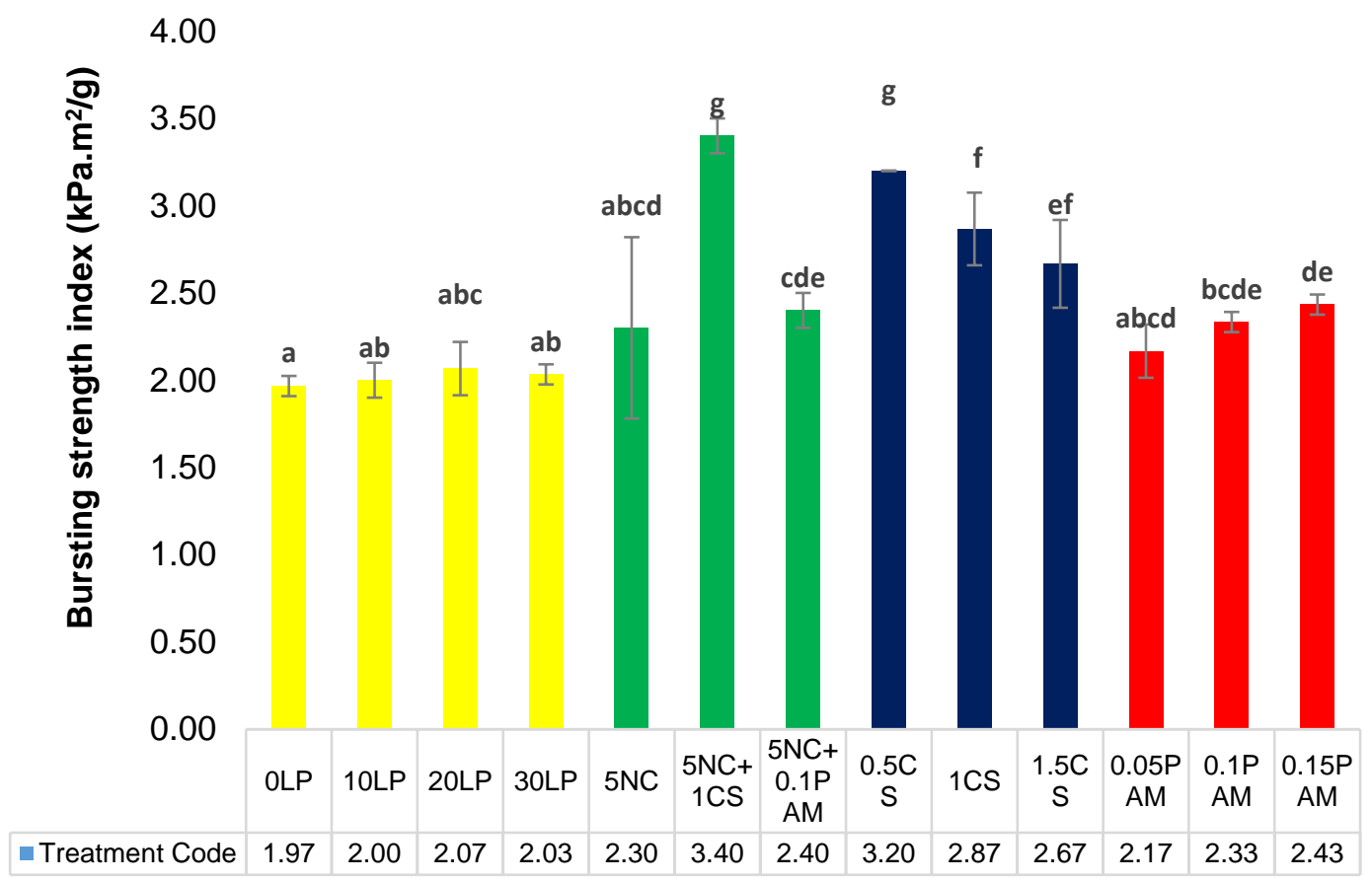

Fig. 4. Mean comparisons of paper bursting strength and grouping the means

The highest bursting strength was obtained when applying cationic starch in combination with 5\% NFC. Cationic starch exhibits high adaptability and tendency to cellulosic fibers, and as a result, contributions from hydrogen bonding, ionic interactions, and covalent joints within the polymeric additives are facilitated (Tajik et al. 2016).

The polyacrylamide, because of its cationic charge, has high adaptability and tendency toward the negatively charged surface of cellulosic fibers, so electrostatic 
connections were facilitated and bursting strength was increased. Generally, the results showed that NFC remained in the paper structure using cationic starch because of its drainage promotion and physical involvement between fibers, the procedure increased the bursting strength. NFC has a high specific surface area and makes a physical involvement between fibers and nanofibers, so it increased the number of hydrogen bonds and increased bonding surface between the fibers. Therefore, the gaps between fibers were reduced. Enhancement of connections between fibers can improve the network power of fibers and such enhancement prevents fiber sliding and leads to an enhancement of fiber network strength (Tajik et al. 2016). Ashori et al. (2006) reported that cationic polymer can connect with cellulosic fibers easily and improve strength characteristics via its positive charge density (Ashori et al. 2006).

\section{Tearing strength index of handsheets}

The main factors affecting tearing strength included the mean of fibers' length and diameter, inherent strength of fibers, the number of joints between the fibers, and the strength of fibers in papermaking, although the amount of components' linking and their orientation in paper structure were also effective. In paper pulps with high connectivity, inherent features of the fiber are a determinant factor, and therefore higher mean length and greater thickness of fibers provides higher tearing strength. Thus, it was expected that the presence of fibers with less length mean and thickness in paper pulp can lead to a reduction of this characteristic.

Figure 5 shows the mean of tearing strength index for 13 types of paper pulp. Duncan's grouping put the mean of tearing strength index into 5 different classes. The highest tearing strength was obtained at Group e when $0 \%$ long-fiber chemical pulp was used. Moreover, inclusion of $30 \%$ imported chemical fiber produced the least tearing strength. In general, the presence of NFC, starch, and polyacrylamide has been found to reduce tearing strength (Fathi and Kasmani 2019; Kasmani and Samariha 2019). A similar trend was reported for the reduction of tearing strength of combined papers and nanocellulosic papers. It seems that more voids were preserved in the paper structure, so the presence of nanofibers and starch and its effect on voids durability, which is compatible with the reduction of wasting materials, can lead to reduction of diameter and length mean of the resulting paper, which is presented as a reduction of tearing index.

In pulp with relatively low bonding ability and low tolerance for refining, such as mechanical pulp, improvement of tearing index through development and enhancement of bonds is possible. But in papers with high bonding level, inherent characteristics of fibers are determining factors, such that longer mean of length and more thickness of fibers provide more resistance against tearing. Therefore, it is expected that the presence of fibers with more length and thickness can lead to enhancement of this characteristic. In treatments with starch percentage less than $0.5 \%$ and combination of starch and NFC, strong and compact flocculation has been formed that has enough energy for breaking stronger flaks and in this aspect, there is not any significant difference between these two treatments and the control treatment. 


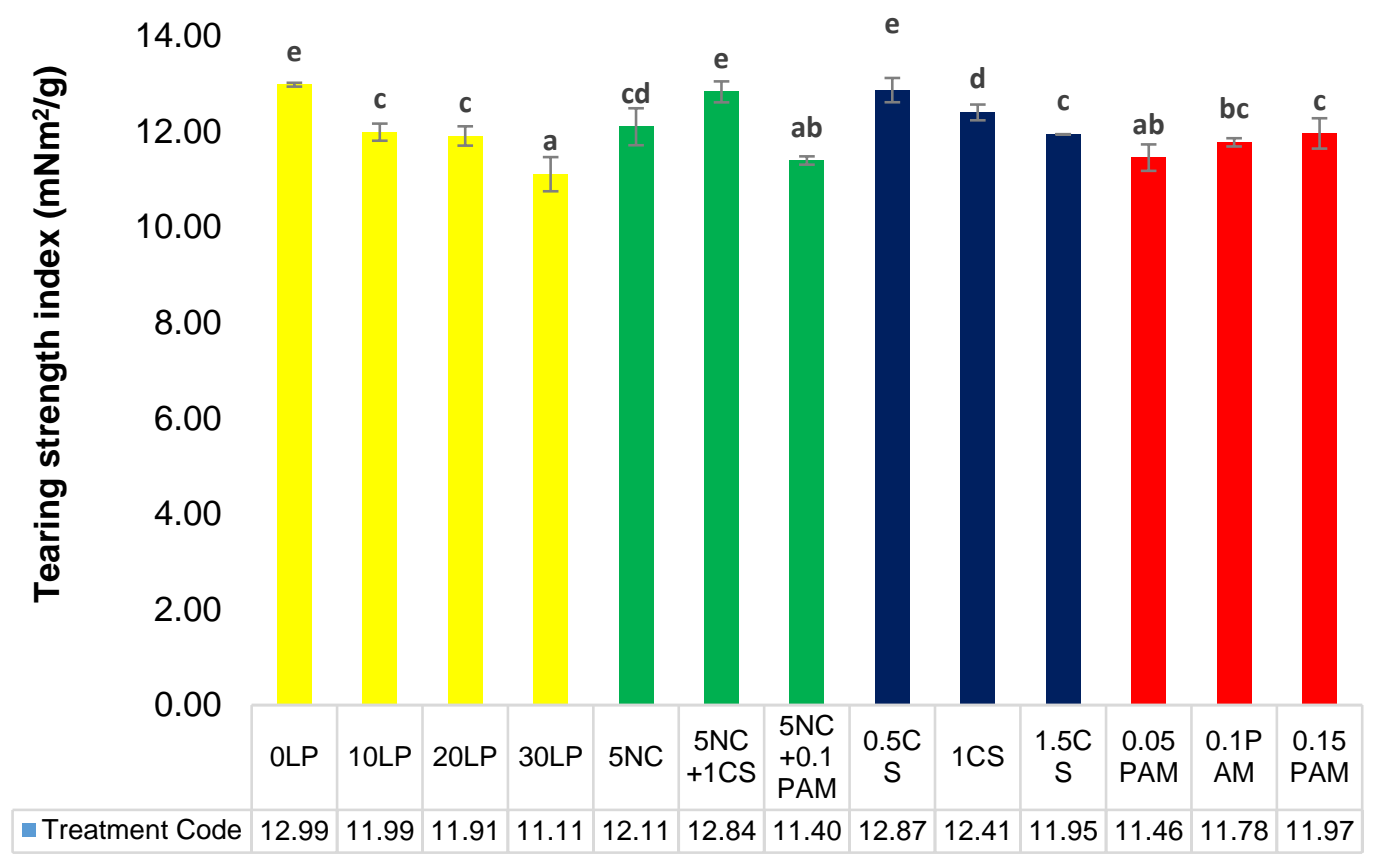

Fig. 5. Mean comparisons of paper tearing strength and grouping the means

\section{Folding strength index of hand sheets}

One of the most complicated mechanical characteristics of papers is its resistance against folding. This index is a crucial index for durable papers, especially currency paper. This strength is affected by fibers' flexibility. In case the fibers are short and the interfiber connection is weak and the fibers are fragile, folding strength will be reduced. Figure 6 shows the mean of folding strength index for 13 types of paper pulp. Duncan's grouping put the mean of folding strength index into 9 different classes. The least folding strength was obtained for Group a by applying 30\% imported long-fibers with the average of 55 double-folds and the highest folding strength was for Group i when $1.5 \%$ cationic starch was used, with 1115 double-folds. The results indicated that the effects of 1 and $1.5 \%$ cationic starch and 0.1 and $0.15 \%$ polyacrylamide were more severe. This can be due to enhancement of fiber specific surface area and strengthening of the fiber network by the means of formation of hydrogen bonds. Increasing starch and cationic polyacrylamide can increase inter-fiber connections and eliminate fiber fragility; all of the procedures increased the folding strength.

The folding strength test is complicated, so that in this test, a combination of resistance to tension, curvature, pressure, other cut stresses are important, and these are affected by relative length. Folding strength has direct relationship with the flexibility of fibers. In this test, fibers are not torn, but gradual reduction in joints between fibers can cause reduction of tensile strength. The first fold cannot affect tensile strength, but after several folds, tensile strength will have become reduced, which can be attributed to fiber stretch.

According to Fig. 6, it can be observed that enhancement of starch percentage individually or in combination with NFC, folding strength of resulted paper will be increased and this may be due to enhancement of fiber flexibility and therefore, the binding between fibers will be increased. 


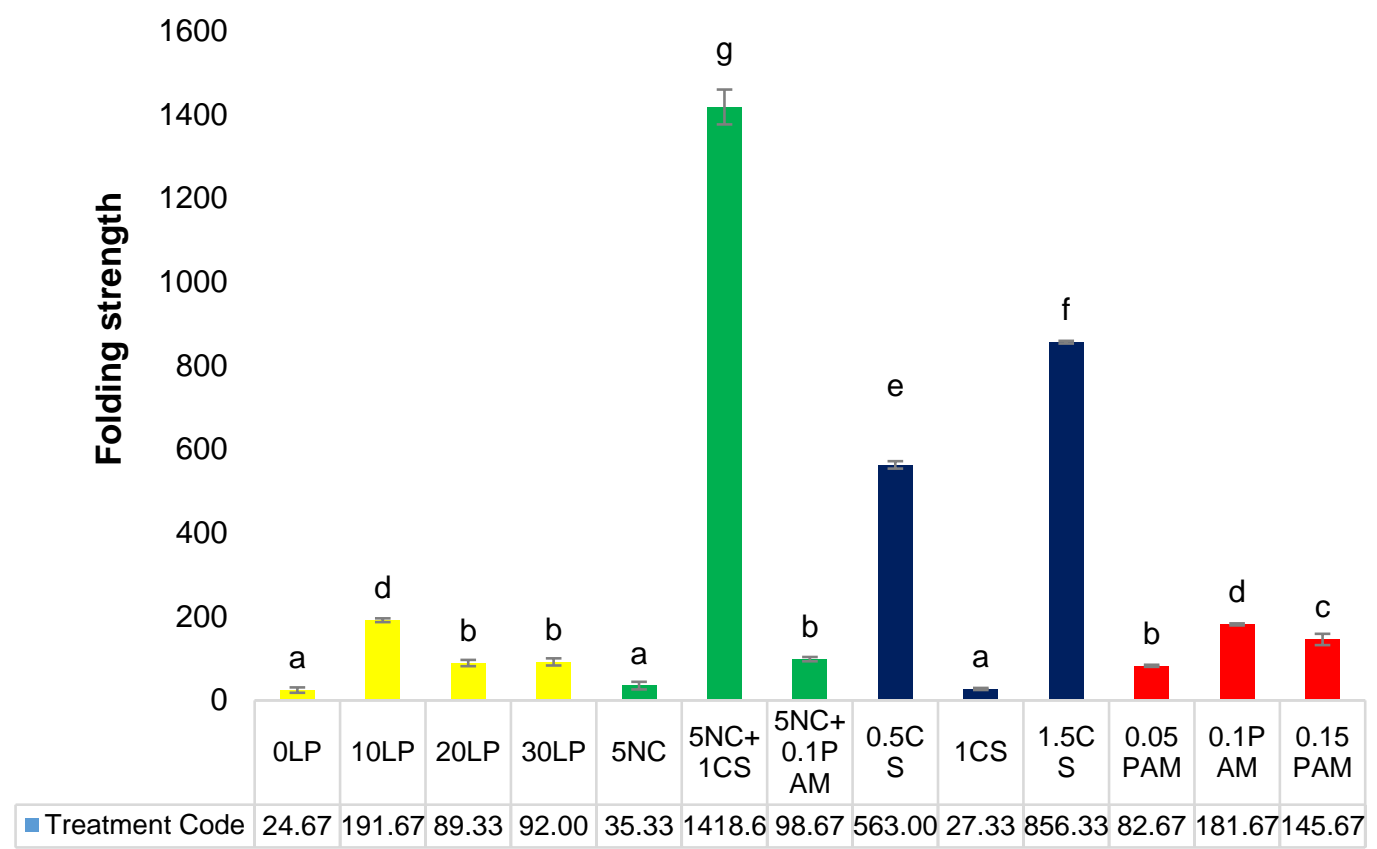

Fig. 6. Mean comparisons of paper folding strength and grouping the means

\section{Optical characteristics of handsheets}

Opacity is an important characteristic in durable papers such as currency paper. Figure 7(a) shows the mean of opacity results for 13 types of paper pulp. Duncan's grouping put the mean of opacity index into 5 different classes. The lowest opacity $(87.3 \%)$ was obtained for Group a, which involved applying 0\% imported long-fibers. Increasing the amount of cationic starch increased opacity. When using NFC separately and in combination with cationic polyacrylamide and in applying $1.5 \%$ starch, the opacity level increased. This implies that there was an increase in gaps within the paper structure. When light enters a gap between the fibers instead of entering directly into another fiber, some of the light becomes scattered.

Brightness degree is the function of optical characteristics of paper pulp and dispersion manner of fillers in the paper (Scott 2005; Yousefi et al. 2011). Figure 7(b) shows the mean of brightness for 13 types of paper pulp. Duncan's grouping put the mean of brightness data into 4 different classes.

The least brightness was obtained by applying 5\% NFC. The brightness changes of paper did not show any specific pattern, and in most cases either it was reduced or it did not have specific changes regarding long-fiber pulp. Slight changes or no change in this characters can only be under the effect of enhancement of between fiber bonds. In other words, the amount of light scattering while the light passes through the paper has direct relation with the level of fibers that are in contact with the air. The less joint surface between fibers, the more surface will be in contact with the air and this unconnected surface can scatter more percentage of light. 


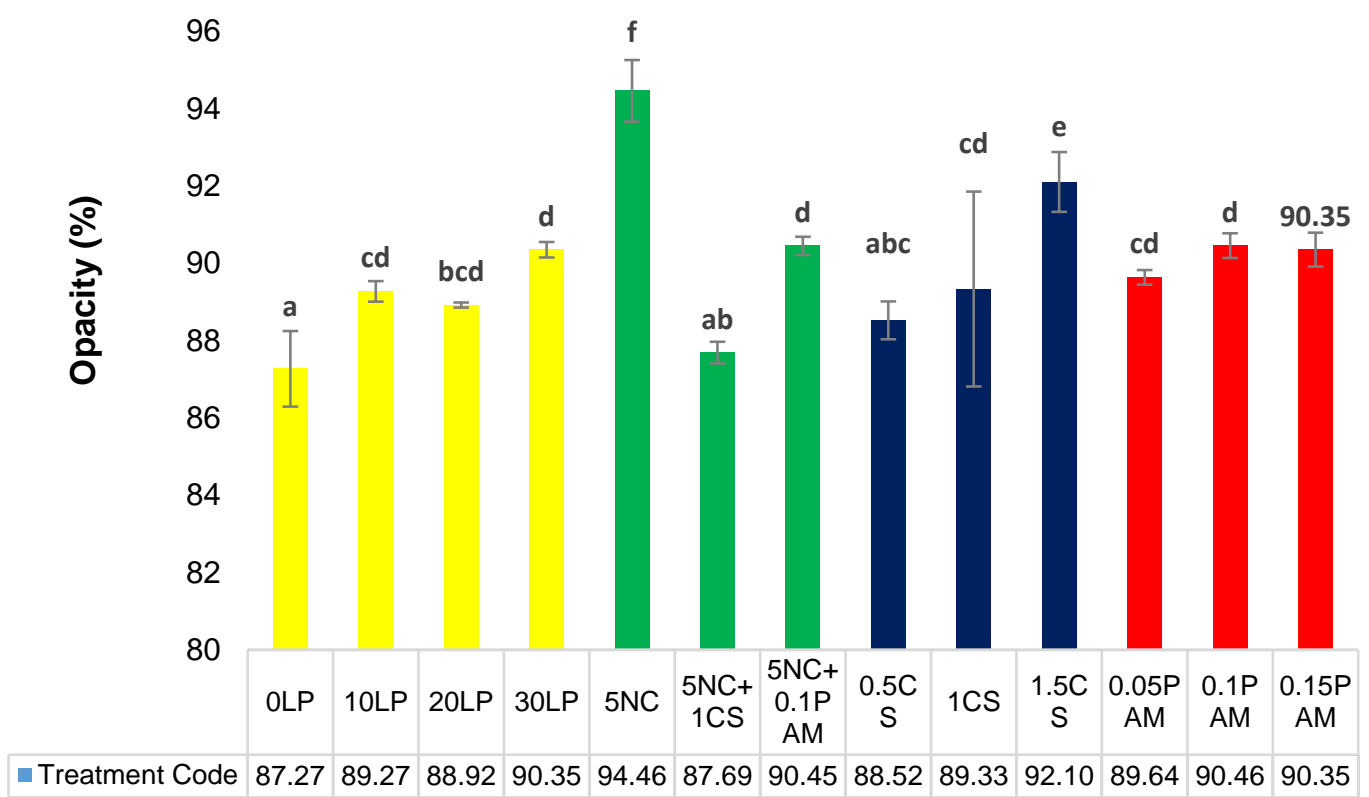

(a)

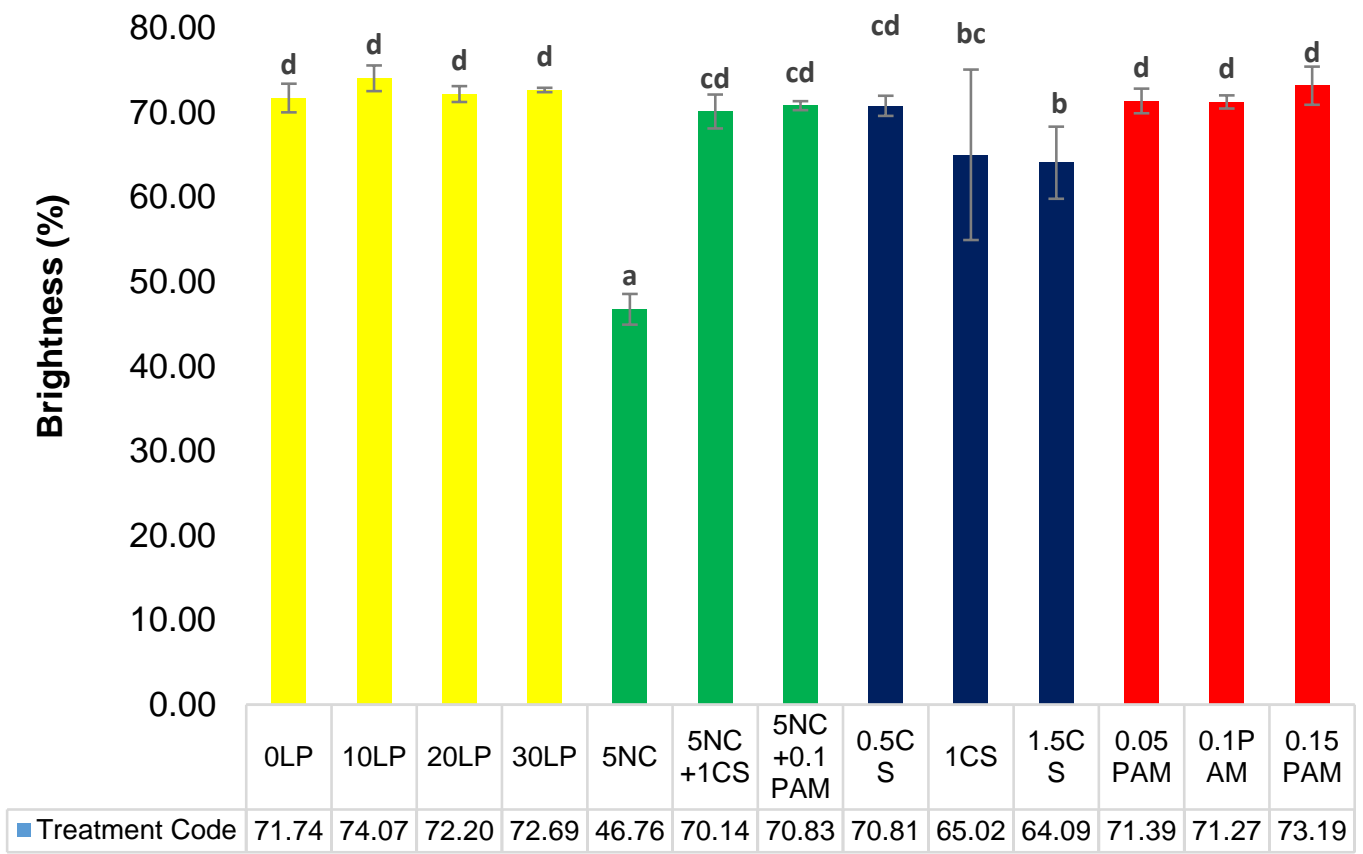

(b)

Fig. 7. The mean comparison of mean grouping a) opacity, and b) brightness

\section{Microscopic studies of paper structure (FE-SEM)}

Figures 8 and 9 indicate FE-SEM for $100 \%$ cotton pulp (0\% chemical pulp), nanocellulosic fibers, and the combination of nanocellulose-starch and nanocellulosepolyacrylamide. There were pores and micrometer-scale roughness in the paper that was prepared from cotton fibers, while in the paper prepared from nanocellulosic fibers and polyacrylamide, pores, and features or roughness were at the nanometer scale. With addition of 5\% nanocellulosic fiber, the surface of paper became smoother and the gaps were relatively filled. Results of surface smoothness and porosity confirm this issue. 


\section{bioresources.com}
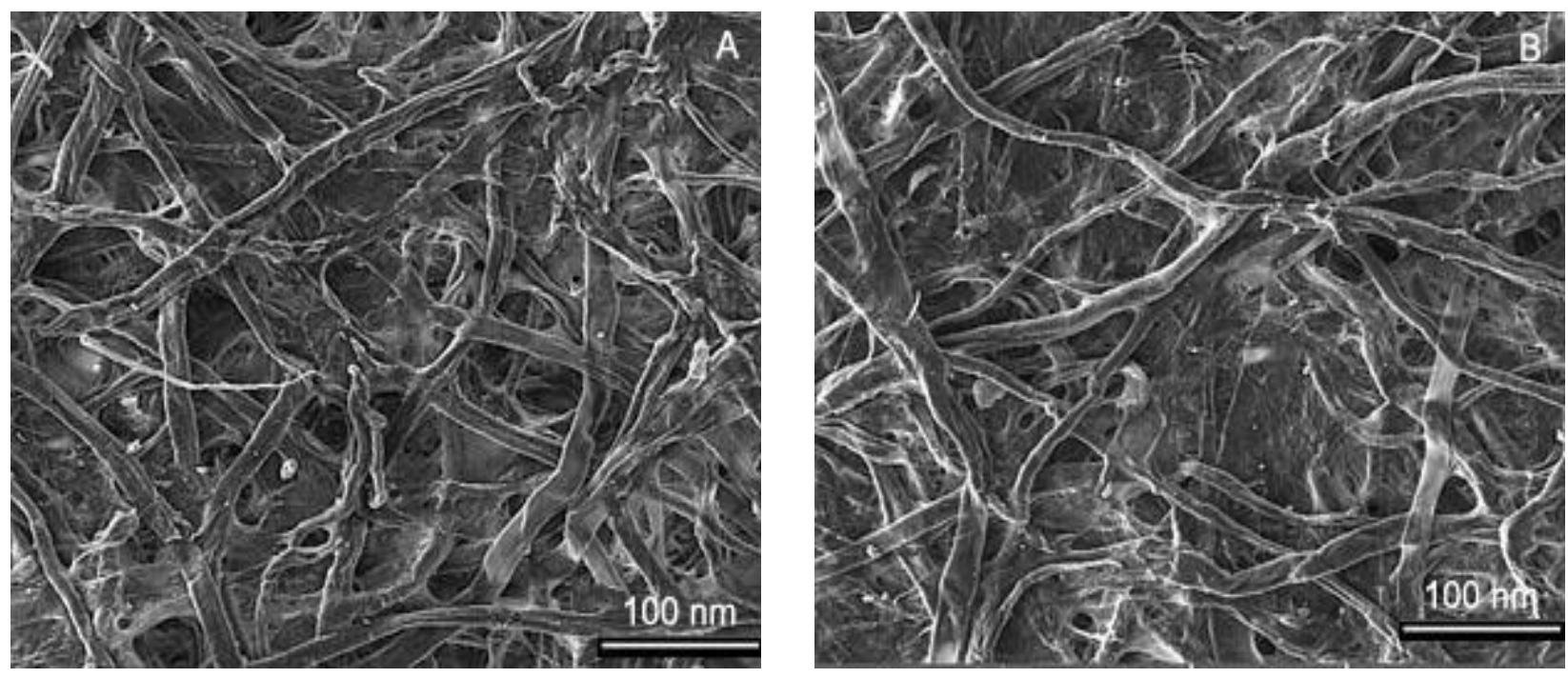

Fig. 8. The surface of paper pulp of a) $0 \%$ chemical pulp and b) $30 \%$ chemical pulp
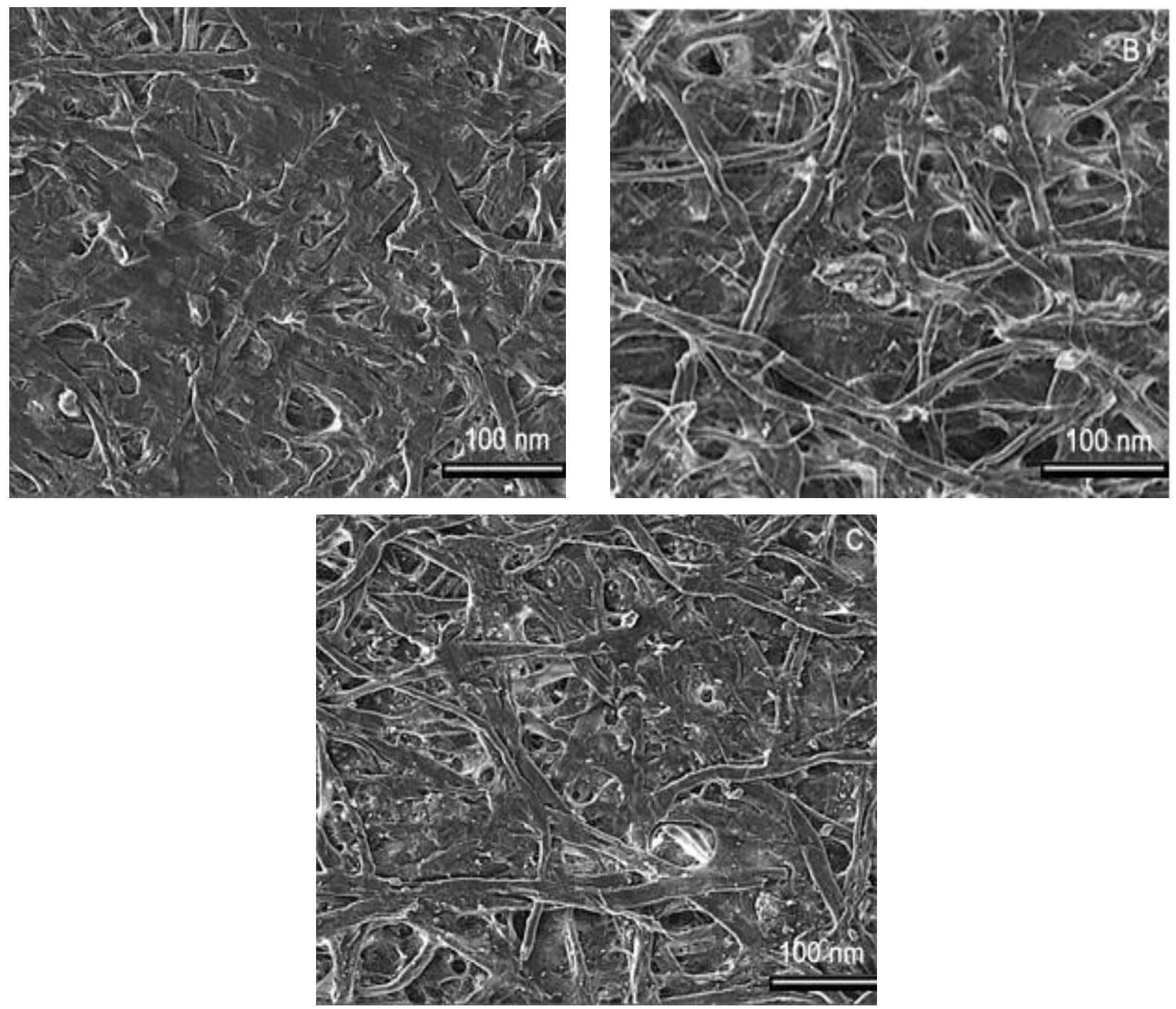

Fig. 9. The surface of paper pulp of a) $5 \%$ nanocellulosic fibers and $1 \%$ starch, b) $5 \%$ nanocellulosic fibers and $0.10 \%$ polyacrylamide, and c) $5 \%$ nanocellulosic fibers 


\section{CONCLUSIONS}

1. Based on the experimental findings, increasing the amount of long-fiber chemical pulp tended to increase the porosity and tearing strength, while smoothness, tensile strength, bursting strength, folding resistance, and opacity were increased.

2. With the increase of nanofibrillated cellulose (NFC) alone, compared to long-fiber chemical pulp, the bursting strength, tearing strength, and opacity increased and the porosity, folding resistance, and brightness decreased.

3. Increasing the amount of NFC in combination with cationic starch reduced the porosity, opacity, and brightness, while the tensile strength, bursting strength, and folding strength were increased.

4. Increasing NFC in combination with cationic starch in comparison with long-fiber chemical pulp reduced porosity, opacity, and brightness, while it increased tensile strength, bursting and tearing strengths, and folding strength.

5. Increasing NFC in combination with cationic polyacrylamide in comparison with longfiber chemical pulp increased opacity, tensile strength, and bursting strength, while porosity, tearing strength, folding strength, and brightness, were decreased.

6. Increasing cationic polyacrylamide, as the only change, increased tensile strength, bursting strength, and opacity, and it reduced porosity and brightness.

7. Increasing cationic starch, as the only change, increased surface smoothness, tensile strength, bursting strength, and folding strength, while it reduced porosity, brightness, bursting strength, and tearing strength.

8. The results of FE-SEM showed that addition of nanocellulosic fibers reduced pore volume of the paper. With NFC addition, the surface became smoother and pores were filled. Results for surface smoothness and porosity confirmed this finding. In total, using a combination of $1 \%$ starch and nanocellulosic fibers showed its applicability for substitution with chemical long-fiber pulp in the production of paper from waste lint.

\section{REFERENCES CITED}

Akbarpour, A., and Resalati, H. (2011). "The effect of different concentrations of cellulase enzyme on optical and physical properties of ONP deinked pulp," Iranian Journal of Wood and Paper Industries 2(1), 1-15.

Asadpour, G., Resalati, H., Dehghani, M. R., Ghasemian, A., and Mohammad Nazhad, M. (2015). "Comparison of using single and dual retention aid system on newspaper pulp properties," Wood and Forest Science and Technology 22(2), 75-93.

Charani, P. R., Dehghani-Firouzabadi, M., Afra, E., Blademo, A., Naderi, A., and Lindström, T. (2013). "Production of microfibrillated cellulose from unbleached kraft pulp of kenaf and Scotch pine and its effect on the properties of hardwood kraft: Microfibrillated cellulose paper," Cellulose 20(5), 2559-2567. DOI: 10.1007/s10570013-9998-z

Elyasi, S., Jalali-Torshizi, H., and Resalati, H. (2016). "Investigation on the effect of different levels of alum consumption in alun-rosin sizing on the properties of plyboard," Journal of Forest and Wood Products 69(2), 375-385. 
Fathi, G., and Kasmani, J. E. (2019). "Prospects for the preparation of paper money from cotton fibers and bleached softwood kraft pulp fibers with nanofibrillated cellulose," BioResources 14(2), 2798-2811. DOI: 10.15376/biores.14.2.2798-2811

González, I., Boufi, S., Pèlach, M. A., Alcalà, M., Vilaseca, F., and Mutjé, P. (2012). "Nanofibrillated cellulose as paper additive in eucalyptus pulps," BioResources 7(4), 5167-5180. DOI: 10.15376/biores.7.4.5167-5180

Hadilam, M. M., Afra, E., and Yousefi, H. (2013). "Effect of cellulose nanofibers on the properties of bagasse paper," Forest and Wood Products 66(3), 351-366.

Hamzeh, Y., and Rostampour-Haftkhani, A. (2008). Principles of Papermaking Chemistry, University of Tehran Press, Tehran, Iran.

Hassan, E. A., Hassan, M. L., and Oksman, K. (2011). "Improving bagasse pulp paper sheet properties with microfibrillated cellulose isolated from xylanase-treated bagasse," Wood and Fiber Science 43(1), 76-82.

Hii, C., Oyvind, W. G., Chinga-Carrasco, G., and Eriksen, O. (2012). "The effect of MFC on the press ability and paper properties of TMP and GCC based sheets," Nordic Pulp \& Paper Research Journal 27(2), 388-396. DOI: 10.3183/npprj-2012-27-02-p388396

Hubbe, M. A. (2005). "Nanotechnology in the wet end," in: Emerging Technologies in Wet-End chemistry, PIRA International Ltd., Leatherhead, England, pp. 3-28.

Hubbe, M. A., and Gill, R. A. (2004). "Filler particle shape vs. paper properties - A review," in: Proceedings of Spring Technology Conference, TAPPI Press, Atlanta, GA, USA, pp. 1-5.

Hubbe, M. A. (2020). "Security papers: Trust but verify," in: Make Paper Products Stand Out. Strategic Use of Wet End Chemical Additives, M. A. Hubbe and S. Rosencrance, S. (eds.) TAPPI Press, Atlanta, GA, Ch. 6, pp. 129-154.

Kasmani, J. E., Mahdavi, S., Alizadeh, A., Nemati, M., and Samariha, A. (2013). "Physical properties and printability characteristics of mechanical printing paper with LWC," BioResources 8(3), 3646-3656. DOI: 10.15376/biores.8.3.3646-3656

Kasmani, J., and Samariha, A. (2019). "Effect of nano-cellulose on the improvement of the properties of paper newspaper produced from chemi-mechanical pulping," BioResources 14(4), 8935-8949. DOI: 10.15376/biores.14.4.8935-8949

Moradian, M. H., Rezayati Charani, P., and Saadatnia, M. (2015). "Improving paper breaking length using cellulosic nanofibers in bagasse pulp," Forest and Wood Products 69(3), 603-614.

Nazeri, A. (2007). "Study the effects of fines particles on properties of physical and optical newsprint made from chemical-mechanical pulp," Iranian Journal of Wood and Paper Science Research 22(1), 29-40.

Petroudy, S. R. D., Syverud, K., Chinga-Carrasco, G., Ghasemain, A., and Resalati, H. (2014). "Effects of bagasse microfibrillated cellulose and cationic polyacrylamide on key properties of bagasse paper," Carbohydrate Polymers 99, 311-318. DOI: 10.1016/j.carbpol.2013.07.073

Rice, M. C., Pal, L., Gonzalez, R., and Hubbe, M. A. (2018). "Wet-end addition of nanofibrillated cellulose pretreated with cationic starch to achieve paper strength with less refining and higher bulk," TAPPI J, 17(7), 395-403. DOI: 10.32964/TJ17.07.395

Rodriguez, J. M. (Ed.). (2005). Micro and Nanoparticles in Papermaking. Tappi Press. Atlanta, GA, USA.

Sehaqui, H., Berglund, L. A., and Zhou, Q. (2013). "Biorefinery: Nanofibrillated cellulose for enhancement of strength in high-density paper structures," Nordic Pulp 
\& Paper Research Journal 28(2), 182-189. DOI: 10.3183/npprj-2013-28-02-p182189

Tajik, M., Resalati, H., Hamzeh, Y., Torshizi, H. J., Kermanian, H., and Kord, B. (2016). "Improving the properties of soda bagasse pulp by using cellulose nanofibers in the presence of cationic polyacrylamide," BioResources 11(4), 9126-9141. DOI: 10.15376/biores.11.4.9126-9141

TAPPI T423 cm-98 (1998). "Folding endurance of paper" TAPPI Press, Atlanta, GA, USA.

TAPPI T205 sp-02 (2002). "Forming handsheets for physical tests of pulp," TAPPI Press, Atlanta, GA, USA.

TAPPI T248 sp-00 (2000). "Laboratory beating of pulp (PFI mill method)," TAPPI Press, Atlanta, GA, USA.

TAPPI T403 om-02 (2002). "Bursting strength of paper," TAPPI Press, Atlanta, GA, USA.

TAPPI T414 om-04 (2004). "Internal tearing resistance of paper (Elmendorf-type method)," TAPPI Press, Atlanta, GA, USA.

TAPPI T452 om-98 (1998). "Brightness of pulp, paper and paperboard (directional reflectance at $457 \mathrm{~nm})$," TAPPI Press, Atlanta, GA, USA.

TAPPI T460 om-02 (2002). "Air resistance of paper (Gurley method)," TAPPI Press, Atlanta, GA, USA.

TAPPI T494 om-01 (2001). "Tensile properties of paper and paperboard (using constant rate of elongation apparatus)," TAPPI Press, Atlanta, GA, USA.

TAPPI T555 om-04 (2004). "Roughness of paper and paperboard (print-surf method)," TAPPI Press, Atlanta, GA, USA.

Yousefi, H., Nishino, T., Faezipour, M., Ebrahimi, G., and Shakeri, A. (2011). "Direct fabrication of all-cellulose nanocomposite from cellulose microfibers using ionic liquid-based nanowelding," Biomacromolecules 12(11), 4080-4085. DOI:

$10.1021 / \mathrm{bm} 201147 \mathrm{a}$

Article submitted: October 24, 2019; Peer review completed: April 10, 2020; Revised version received: July 8, 2020; Further revised version received and accepted: August 10, 2020; Published: September 25, 2020.

DOI: $10.15376 /$ biores.15.4.8601-8616 